$\begin{array}{ll} & \text { Etnográfica } \\ \text { etnográfica } & \text { Revista do Centro em Rede de Investigação em }\end{array}$

Antropologia

vol. $24(1) \mid 2020$

Vol. 24 (1)

\title{
Los acentos del medio ambiente: procesos de ambientalización, fuerza social y articulación discursiva en la Sierra Morena andaluza
}

The accents of the environment: processes of environmentalisation, social force and discursive articulation in the Andalusian Sierra Morena

\section{Ernesto Martínez Fernández}

\section{(2) OpenEdition}

\section{Journals}

\section{Edición electrónica}

URL: https://journals.openedition.org/etnografica/8206

DOI: 10.4000/etnografica.8206

ISSN: 2182-2891

\section{Editor}

Centro em Rede de Investigação em Antropologia

\section{Edición impresa}

Fecha de publicación: 1 febrero 2020

Paginación: 49-68

ISSN: 0873-6561

\section{Referencia electrónica}

Ernesto Martínez Fernández, «Los acentos del medio ambiente: procesos de ambientalización, fuerza social y articulación discursiva en la Sierra Morena andaluza», Etnográfica [En línea], vol. 24 (1) | 2020, Publicado el 25 febrero 2020, consultado el 19 enero 2022. URL: http://journals.openedition.org/ etnografica/8206 ; DOI: https://doi.org/10.4000/etnografica.8206

\section{(c) (†) 8}

Etnográfica is licensed under a Creative Commons Attribution-NonCommercial 4.0 International License. 


\section{Los acentos del medio ambiente: procesos de ambientalización, fuerza social y articulación discursiva en la Sierra Morena andaluza}

\section{Ernesto Martínez Fernández}

La interiorización de prácticas y lenguajes de carácter ambiental por parte de los sectores agrarios que habitan en áreas naturales protegidas constituye un fenómeno ampliamente constatado por la literatura antropológica. Este artículo analiza la particular versión de ese proceso encontrada entre los ganaderos de un parque natural de la Sierra Morena andaluza. Se sostiene que dicha "ambientalización" está estrechamente relacionada con el peso que las intervenciones estatales - y sus transformaciones - tienen en la estructuración de la realidad agraria local. El fenómeno, además, se manifiesta predominantemente en las arenas donde ganaderos y agentes de dichas intervenciones se enfrentan. El artículo, en ese sentido, explora la relacionalidad del significante ambiental en el seno de esas luchas y destaca la importancia de su articulación con elementos clave del "sentido común" (en sentido gramsciano). Se argumenta que estos discursos son capaces de re-significar las premisas de las narrativas ambientales "institucionalizadas", construyendo así nuevos ambientalismos que emergen desde el mismo interior del medio rural.

PALABRAS CLAVE: ambientalización, áreas naturales protegidas, articulación discursiva, desarrollo sostenible, etnografía, España.

The accents of the environment: processes of environmentalisation, social force and discursive articulation in the Andalusian Sierra Morena - The embracing of environmental practices and languages by the agrarian sectors that inhabit natural protected areas is a phenomenon broadly confirmed by anthropological literature. This article analyses the specific version of that process encountered among farmers of a natural park located in the Andalusian Sierra Morena. That "environmentalisation," it is argued, is closely linked to the weight that state interventions - and its transformations - have on the shaping of local reality. Moreover, the phenomenon takes place mainly within the arenas of confrontation between farmers and agents of those interventions. The article explores the relationality of the environmental significant within those struggles and highlights the relevance of its articulation with key elements of "common sense" (in a Gramscian sense). These discourses, it is argued, are able to re-signify the premises of "institutionalised" environmental narratives, thus shaping new grassroots environmentalisms.

KEYWORDS: environmentalisation, natural protected areas, discursive articulation, sustainable development, ethnography, Spain.

MARTÍNEZ FERNÁNDEZ, Ernesto (emarfer2@upo.es) - Universidad Pablo de Olavide, España. 


\section{INTRODUCCIÓN}

Una mañana cualquiera se encontraba Tomás en el carril que conducía a una de las fincas que arrendaba para sus ovejas en Cazalla de la Sierra, municipio enclavado en un parque natural (PN) de la Sierra Morena andaluza. ${ }^{1}$ Tenía intención desde hacía varios días de "limpiar" las zarzas que habían crecido bajo las dos hileras de álamos que flanqueaban ese tramo del camino. Por fin había encontrado un momento. Mientras las cortaba, pasó por allí el propietario de una finca cercana, Marcos. Este "vecino" no era ganadero, sino médico. Tampoco vivía de manera permanente en la localidad. Aunque creció en ella, después de irse a estudiar a la ciudad pasó a establecerse en el municipio donde consiguió su plaza de funcionario. Ahora bien, nunca había cortado el vínculo con su pueblo de origen. Marcos, además, era un personaje relativamente célebre por su activismo en el movimiento ecologista andaluz.

Quizás fuera éste el motivo que lo llevó a parar el coche y pedirle a Tomás que no siguiese cortando las zarzas. El ganadero le preguntó la razón y Marcos le explicó que las zarzas jugaban un papel muy importante en el mantenimiento de la diversidad de especies de los campos circundantes. Tomás replicó que dejar las zarzas allí significaría arriesgarse a que cualquiera se pinchase. Le preguntó si creía que dejar las zarzas sin cortar le hacía más "ecológico", la palabra que Tomás emplea para referirse a ecologista. Sin esperar la posible respuesta, el ganadero sacó unas bellotas que casualmente tenía en el bolsillo y le espetó: "Mira, éste es el ecológico. Que fui allí, en aquella barranca, y siembro una bellota. Allí, a lo mejor, siembro otra. Pero, ¿tú? ¿Sabes el ecológico que eres tú? Un ecológico de cartera. Que todos los meses no te falten los billetes". Marcos, indignado, no quiso responder. Volvió al coche y al parecer no ha vuelto a dirigirle la palabra a Tomás. ${ }^{2}$

Esto me contaba este último durante una entrevista. Quizás el choque con Marcos no se produjera exactamente así; quizás sí. De cualquier manera, lo que me interesa del mismo no es tanto su veracidad como el hecho de que, en la disputa, el argumento empleado por el ganadero sea de carácter claramente ambiental: la siembra de bellotas en diferentes zonas con pendiente, presumiblemente con la intención de amortiguar las dinámicas erosivas. Ello

I Este artículo ha sido realizado en el marco de mi tesis doctoral, financiada por una beca del programa de Formación de Profesorado Universitario (FPU 12/01132) del antiguo Ministerio de Educación, Ciencia y Deporte español. Comenzó a gestarse durante una estancia de investigación desarrollada entre los meses de abril y julio de 2016 en la Wageningen University (Países Bajos) bajo la supervisión de la doctora Monique Nuijten, a quien expreso mi agradecimiento por las valiosas críticas realizadas al primer esbozo. También agradezco a los dos evaluadores anónimos de Etnográfica, así como a su comisión editorial, por sus sugerencias, las cuales me han ayudado a mejorar sustancialmente la primera propuesta enviada a la revista. Los posibles errores que puedan encontrarse serán, en todo caso, de mi única responsabilidad.

2 Con el fin de mantener el anonimato de mis interlocutores, usaré seudónimos. 
es indicativo de un proceso local de ambientalización (Lopes 2006), que será precisamente el objeto de interés de este artículo. Por ambientalización entiendo el proceso de interiorización de prácticas y lenguajes asociados al medio ambiente en tanto formación discursiva y "cuestión pública" (Lopes 2006: 34).

El medio ambiente, como consecuencia del fulgurante éxito inicial del nuevo ecologismo surgido en la década de 1960, se ha convertido en un objeto normalizado de preocupación social (Lopes 2006; Santamarina 2006). Dicha normalización ha sido tan profunda que podría decirse que ha implicado la conversión de la dupla preocupación ambiental-sostenibilidad - sostenibilidad entendida como el anverso de carácter propositivo de la idea de medio ambiente (Santamarina 2006) - en todo un nuevo "anhelo social" (Žižek 2003 [1997]), al nivel de otros como justicia, libertad o democracia. Ahora bien, al igual que dichos anhelos, en ese camino de normalización, la original preocupación ambiental no ha quedado indemne: su estrecha conexión con la crítica del capitalismo se ha debilitado hasta convertirse en una suerte de significante ambiguo o, en palabras de Žižek, de "significante no-ideológico" (2003 [1997]: 142).

El hecho de que la interiorización local de lo ambiental a la que el relato de Tomás apunta se produzca en un PN no resulta una excepción. Si bien pudiese parecer a primera vista que el usual rechazo de los sectores locales afectados por las iniciativas de patrimonialización natural podría conllevar la aversión hacia el discurso ecológico en que se apoyan, los hallazgos de la antropología de la conservación señalan en la dirección contraria (Agrawal 2005; Anaya y Espírito-Santo 2018; Whitehouse 2009). Para el contexto etnográfico en el que tuvo lugar la investigación de la que parte este artículo, el fenómeno ambientalizador también ha sido comprobado de manera recurrente, como ponen de manifiesto los estudios de Coca (2014), Cortes-Vazquez (2012), Díaz, Santana y Rodríguez (2015), Ruiz-Ballesteros et al. (2009), o Santamarina y Beltran (2016).

Uno de los marcos que más fortuna han hecho en el análisis de este tipo de procesos es el de la llamada environmentality. En el desarrollo del mismo, Agrawal (2005) es, sin duda, el estudioso de referencia. En un trabajo realizado a partir de material producido en el norte de la India, su objetivo era explicar el tránsito de una población históricamente rebelde hacia la asimilación de representaciones ambientales y prácticas de relación humano-forestal asociadas al conservacionismo occidental. Para el autor, el hecho clave sería la adopción por el Estado de un modelo de conservación comunitária (community-based conservation). Ello implicaba la descentralización de la gestión de la protección a "consejos forestales" compuestos por técnicos de la administración y habitantes. Sin poder salirse de la normativa ambiental, estos órganos se encargarían de desarrollar una regulación propia del uso de los bosques, así como de vigilar 
su cumplimiento. Este "gobierno íntimo" sería precisamente el que permitiría vencer la secular resistencia al Estado, materializada en la adopción por los habitantes locales de la particular "subjetividad ambiental" promovida por el mismo Estado. Para el éxito de este ejercicio gubernamental (en sentido foucaultiano), las nuevas prácticas promovidas por los consejos forestales serían fundamentales, al constituir el medio por el que nuevos intereses eran generados y actuaban como el campo fértil para aquella subjetividad. ${ }^{3}$

Desde dos contextos etnográficos situados ahora en Europa - ambos en Andalucía -, Ruiz-Ballesteros et al. (2009) reflexionan sobre el proceso de "naturalización" por el que ex-mineros y ex-agricultores asimilan la categoría "naturaleza" en sus percepciones y representaciones de unos territorios marcados por el abandono productivo y la turistización. Para estos autores, el efecto combinado del fin de la actividad transformadora del medio y el contacto con la mirada del turista, característicamente paisajística, ha conducido a un cambio en su "marco perceptivo" que sirve de base a aquella reinterpretación del entorno. Ahora bien, sus "naturalezas" tendrían poco que ver con las de los discursos turísticos en boga, que, en el primer caso, presentarían al paisaje minero como lo opuesto a la idea de naturaleza; y, en el segundo, presentarían lo que fue un paisaje agrario como una naturaleza desértica prístina. Frente a estas lecturas, las naturalezas de los ex-mineros y ex-agricultores tendrían en común su dependencia de la intervención humana. El carácter inherentemente antrópico de dichas representaciones "reaffirms the position regarding/ within the environment by questioning 'official' nature from local naturalization $[\ldots]$ and is associated with identity-shaping processes" (Ruiz-Ballesteros et al. 2009: 163).

El proceso de ambientalización que se analizará en este artículo se distancia de los territorios de los que parten ambos trabajos - aún situándose, como el segundo, en la comunidad autónoma de Andalucía - en que, respecto al primero, se produce en un área natural protegida (ANP) impuesta "desde arriba” y sin participación local efectiva; y, en relación al segundo, en que sus

3 Agrawal y el marco de la environmentality han recibido duras críticas (Cepek 2011; Silva 2015). Cepek (2011), por ejemplo, analiza otro caso de conservación comunitaria - esta vez en Ecuador a partir de una inmersión en las formas como los pobladores locales se relacionan con el personal científico y las tareas de conservación. En lugar de producirse una sujeción, Cepek sostiene: "Cofán project workers maintain a critical consciousness of the activities, relations, instruments, and products of scientific conservation. [...] As long as they receive some portion of the political-economic resources that they seek, Cofán people are more than willing to devote themselves to a form of labor that they continue to experience as burdensome and oriented to community-external rather than communityinternal logics and needs" (Cepek 2011: 512). El empobrecimiento etnográfico al que Cepek apunta, ya señalado por otros autores (De Vries 2005), ha llevado en los últimos años a varias tentativas de repensamiento del marco de la environmentality para intentar dar cabida a la agencia y la resistencia (Cortes-Vazquez y Ruiz-Ballesteros 2018; Singh 2013). 
protagonistas son ganaderos en activo y plenamente vinculados a una experimentación y transformación cotidiana del entorno. Sea por estas diferencias o no, lo cierto es que su particular interiorización de lo ambiental no parece derivar de la asimilación de una subjetividad ambiental o de la generación de nuevos esquemas perceptivos. Lo que se argumenta en el artículo es, de manera muy sintética, que el fenómeno en este caso tiene que ver con la construcción de discursos políticos con los cuales los ganaderos participan de manera eficaz en el "campo de fuerzas" (Nuijten 2005) agrario en que se juegan la continuidad de su oficio y su modo de vida.

\section{VERDE QUE TE QUIERO VERDE}

Cazalla de la Sierra tiene una población de alrededor de 5000 habitantes. Los agroecosistemas locales se distribuyen siguiendo el patrón típico en la mitad occidental del macizo de Sierra Morena: un núcleo urbano rodeado de huertas y olivares, y un segundo anillo conformado por fincas de dehesa con diferentes intensidades de intervención humana. El modelo clásico de dehesa consiste en un bosque de quercíneas - encinas y alcornoques, principalmente - cuyo estrato arbustivo es eliminado de manera periódica para permitir el aprovechamiento ganadero extensivo de pastos y frutos (Acosta 2002). Partiendo del importante nivel de autosuficiencia, mosaicidad y biodiversidad de esta dehesa, muchos académicos han venido señalando a este agroecosistema como un paradigma de la sostenibilidad agraria (Acosta 2002; Joffre et al. 1988).

En la actualidad, buena parte de las grandes dehesas locales (>500 ha), mayoritariamente poseídas por absentistas foráneos, presenta un avanzado estado de matorralización como consecuencia de su conversión en cotos de caza mayor. Por su parte, las dehesas en manos de propietarios locales, de menor dimensión ( $<500$ ha), se mantienen en producción, habiendo transitado en las últimas décadas hacia un manejo semiextensivo y un cierto abandono del sistema periódico y rotativo de desmatorralización. La actividad ganadera en torno al cerdo ibérico, la oveja y, en menor proporción, la cabra, que se desarrolla en estas dehesas sigue constituyendo, a pesar del creciente desarrollo turístico, el principal sector económico de la localidad.

Basada en buena medida en el mencionado discurso de excepcionalidad ecosistémica de la dehesa, se produjo en 1989 la declaración como PN de Cazalla de la Sierra y el resto de su comarca. A pesar de que la mayoría del territorio a proteger era privado y de que una parte importante de los obreros locales siguiera ganándose la vida de manera estacional en este medio - trabajando en la tala, el descorche, la recolección de aceituna o el arranque de matorral, pero también a través de actividades “informales” como la recolección de espárragos y setas -, el gobierno andaluz procedió a la declaración sin mediar ningún proceso participativo, negociador o siquiera consultivo. 
Sería con la aprobación de la Ley Forestal andaluza de 1992 y, dos años después, con la del Plan de Ordenación de los Recursos Naturales (PORN) y el Plan Rector de Uso y Gestión (PRUG) que la presencia del PN empezaría a ser experimentada como claramente problemática. Por un lado, casi todos los trabajos a realizar en la dehesa pasaron a estar supeditados a una autorización administrativa que centralizó el PN. Tal burocratización, junto a los retrasos en la aprobación de solicitudes que la acompañaron, contribuyó a la asociación en el imaginario local del PN con un obstáculo. Por otro lado, la nueva legislación contenía una serie de prohibiciones y limitaciones a las prácticas agrarias, como la desaparición del arado en pendiente, la restricción a ciertos cambios de uso del suelo, la necesaria supervisión de talas por los efectivos de guardería rural del PN (los llamados "agentes de medio ambiente"), etc., las cuales ahondaron en la sensación de ataque a la autonomía ganadera. El resultado fue el desarrollo de un fuerte rechazo, sustanciado en un repertorio político que viene abarcando desde clásicas formas de "resistencia cotidiana" (Scott 1985) hasta la lucha discursiva abierta.

Es evidente que la relectura académica de la dehesa en términos ecológicos y su asimilación por parte del PN en tanto elemento fundacional y base legitimadora de su actuación constituyen importantes factores a la hora de entender el proceso de ambientalización de los ganaderos locales. Ahora bien, también deben tenerse en cuenta otras fuentes, como la omnipresencia mediática de la cuestión ambiental (Lopes 2006; Santamarina 2006) y, en especial, la propia ambientalización experimentada por la Política Agrícola Común (PAC). Esto último tiene que ver con el cuestionamiento de la PAC en el contexto de la neoliberalización global y el subsiguiente blindaje operado por las autoridades europeas a través de los resquicios dejados por los acuerdos comerciales multilaterales (García 2005). Permitiendo éstos la ayuda directa a la renta, la PAC procedió a su desvinculación respecto a los resultados de la actividad agraria. Asimismo, la tolerancia de los mencionados acuerdos hacia las ayudas orientadas a la protección ambiental condujo a la implementación de una "ecocondicionalidad" a la que se debían someter las explotaciones solicitantes de ayuda. También, derivó en la creciente relevancia otorgada al programa de ayudas agroambientales y, en su seno, a los esquemas de agricultura y ganadería ecológica.

La importancia de la PAC proviene de la profunda dependencia que el medio rural europeo tiene respecto a ella para el mantenimiento de sus poblaciones. En el caso de las explotaciones de Cazalla de la Sierra, la PAC supone para la mayoría de los medianos y pequeños ganaderos la fuente de una importante parte - entre el 30 y el $60 \%$ - de la renta agraria. Si tenemos esto en cuenta, será posible dimensionar la relevancia de la ambientalización de la PAC en el proceso de alteración de las "reglas del juego" del campo agrario (Sutherland y Darnhofer 2012: 234), el cual implica, en lo fundamental, una relectura por la que el agro se convierte en "medio ambiente". 


\section{UN OTRO AMBIENTALISMO}

En los inicios de mi trabajo de campo en Cazalla de la Sierra, asistí a una charla informativa organizada por la organización ecologista Fondo Mundial para la Naturaleza (WWF) en colaboración con el Grupo de Desarrollo Rural comarcal. La actividad tenía por objetivo explicar los beneficios de acogerse a una "certificación de la gestión forestal responsable". Ello suponía la obtención del sello FSC, un distintivo que, según los organizadores, ayudaba a conseguir mejores precios para productos forestales como la madera o el corcho. Dadas las expectativas de mayores ingresos, la exposición del ponente parecía suscitar el interés de un público formado netamente por ganaderos locales.

La ilusión se evaporó cuando el ponente se refirió al mínimo de hectáreas que debían poseer las explotaciones solicitantes de certificación. El número que ofreció dejaba fuera, en la práctica, a todas las explotaciones pequeñas y parte de las medianas. Aunque decía que era posible la agrupación de fincas a efectos de certificación, ni el valor a pagar en esta modalidad ni la idea de compartir un compromiso parecían convencer a unos ganaderos poco propensos a este tipo de empresas colectivas. En una población marcada, como muchos otros territorios del suroeste peninsular, histórica y culturalmente por el latifundismo, el sentir general en la sala era de malestar por una ventaja que parecía diseñada a la medida de los grandes propietarios.

El primer ganadero que hizo uso del turno de palabra comenzó diciendo que, según tenía entendido, "en época de los romanos, España entera era un puro bosque”. En la actualidad, sin embargo, cada vez había menos árboles y sostenía que ello se debía en buena medida a los incendios que asolaban el país cada verano. En el caso de las dehesas, ese fenómeno tendría que ver con la falta de labores y de ganado, y el consiguiente avance del matorral, que se concentraría en unas grandes fincas caracterizadas por un abandono que, en lugar de ser penalizado por el Estado, era promovido por las políticas agrarias y por el PN. A los grandes propietarios se dirigirían las ayudas más cuantiosas y ellos eran los que se beneficiaban de muchos de los programas de desarrollo rural por su capacidad para contratar técnicos "cazasubvenciones" para la redacción de las solicitudes.

A diferencia de esos "señoritos", eran los "ganaderos de verdad" quienes mantenían, con su gestión y su trabajo, las dehesas limpias y protegidas de los incendios. Ellos sí arrancaban y desbrozaban el matorral que recurrentemente genera el suelo. A ello se sumaba la acción del ganado, clave para mantener el matorral a raya. Como consecuencia, el ganadero decía que ellos debían ser considerados "bomberos de la naturaleza", pero que, en lugar de eso, eran "maltratados por las administraciones y atacados por los ecologistas".

En esta viñeta, encontramos una potente ilustración del proceso de ambientalización local. En el discurso del ganadero, la intervención agraria sobre el 
medio no pasaría por ser una mera actividad económica, sino que se trataría, sobre todo, de una acción de protección del medio ambiente. Si en el caso de Tomás este proteccionismo se relacionaba con el freno a la erosión, aquí la prevención sería respecto a los incendios forestales. Y la lectura de la ganadería en tanto labor preventiva se lleva tan lejos como para adoptar la autodefinición de "bomberos de la naturaleza". Lo que queda patente es que la ambientalización de estos productores es inseparable de su afirmación en tanto ganaderos. Al contrario que lo apuntado por Agrawal (2005), aquí la intervención ambiental no deriva en la construcción de un nuevo "interés", sino que parece ser un interés preexistente - el de la defensa de la pervivencia de sus explotaciones el que sirve de impulso a una ambientalización que se usa para contestar la propia intervención ambiental.

Desde luego, en este proceso puede estar operando paralelamente un cambio a nivel perceptual similar al descrito por Ruiz-Ballesteros et al. (2009). En muchas ocasiones, me encontré durante el trabajo de campo con valoraciones de tipo paisajísitico y/o estético por parte de mis interlocutores que indicaban la asimilación de esa perspectiva contemplativa a la que aluden estos autores. No obstante, resulta difícil afirmar una relación causal entre cambio perceptual y ambientalización para este caso. ¿Por qué no a la inversa? ¿No es plausible también que la adopción del léxico y prisma ambientales, como respuesta a la relectura de la actividad agraria por los distintos vectores de intervención sobre el medio rural, sea la que derive en el desarrollo de percepciones de tipo paisajístico?

Sea como fuere, y más allá de la pregunta sobre la relación entre percepción y representación, lo más significativo del fenómeno ambientalizador objeto de análisis es su claro carácter político. Y lo que parece que encontramos entre los ganaderos de Cazalla es la adopción y simultánea resemantización de lo ambiental con la finalidad, precisamente, de evitar y/o amortiguar la pérdida de autonomía ganadera como consecuencia de la cada vez más intensa intervención estatal. Es en este sentido que el fenómeno resuena con el concepto de "táctica" de De Certeau (1984 [1980]). ${ }^{4}$

Algo a destacar, indicativo del profundo carácter político del fenómeno, es la centralidad que en su materialización ocupan los llamados "ecologistas". Hay que puntualizar que el término "ecologistas" suele emplearse localmente como una categoría que agrupa indistintamente a todas aquellas personas que se asocian a un conservacionismo oficialista y que pueden ir desde el personal del PN hasta activistas del asociacionismo ecologista local y externo. Considerándose, de manera general, a estos "ecologistas" como el paradigma de los defensores de la protección ambiental, resulta obvio que la disputa de ese papel por parte de los ganaderos se realice frente a ellos. Recordemos que, en el

4 De Certeau entendía que "[t]he space of a tactic is the space of the other. Thus it must play on and with a terrain imposed" (1984 [1980]: 37). 
relato de Tomás, éste se afirmaba como el verdadero "ecológico" en oposición al "ecológico de cartera" que sería Marcos.

Otro elemento clave que no debe perderse de vista es el hecho de que la resemantización de lo ambiental en que consiste el fenómeno no se produce en sí misma. Si volvemos a la charla sobre certificación forestal, nos daremos cuenta de que el ganadero interviniente, aparte de leer en términos ambientales su actividad productiva y cargar contra "ecologistas" y administración, conectaba su discurso con un elemento profundamente arraigado en las clases subalternas del occidente andaluz: la impugnación del latifundismo. Ello nos vuelve a hablar de aquel "interés" al que hacía referencia más arriba, pero también apunta hacia una particular construcción discursiva que parece requerir, para ser efectiva, de anclajes en el "repertorio cultural" (Long 2001) de estos ganaderos.

Teniendo esto en cuenta, y con el fin de estar en disposición de dar un paso más en el análisis del fenómeno, necesitamos recurrir a una perspectiva teórica que se interese a la vez por la maleabilidad de los elementos discursivos y la dialéctica entre "interés" y lucha social. Considero que la versión de la teoría laclauiana de la articulación desarrollada por Stuart Hall constituye una excepcional opción. A su síntesis dedico el próximo apartado, en el cual aprovecho para complementarla con los insights de Žižek en relación al ya referido concepto de "significante no-ideológico".

\section{ARTICULACIÓN Y PERLABORACIÓN}

Según Laclau (1978), los discursos ideológicos no constituyen unidades o bloques más o menos coherentes y estables, sino que consisten básicamente en articulaciones contingentes de elementos ideológicos diferentes y, a veces, contradictorios. Estos elementos no poseen ninguna adscripción o connotación política fija, siendo precisamente su articulación la que les conferiría un sentido siempre situado y provisional. Ahora bien, ello no supone que las posibilidades discursivas, si bien amplias, sean infinitas. A diferencia de su evolución posterior (Laclau 2005), el primer Laclau sostenía que los discursos sólo pueden producirse alrededor de las clases sociales fundamentales - burguesía y proletariado -, las cuales actuarían como los ejes o "principios articulatorios" a través de sus respectivas ideologías de clase (Laclau 1978: 103-126, 154-164).

Fascinado por los Quaderni del Carcere de Gramsci, Hall observa en la teoría de la articulación de Laclau el mejor complemento para la visión gramsciana de la ideología como "combinación" de elementos (Gramsci 1984: 315). Al mismo tiempo, Hall trasciende el determinismo clasista por el que las clases eran los "principios" necesarios de las construcciones discursivas. Sin omitir la importancia de las relaciones sociales de producción (Hall 1988: 44-45), prefiere entender éstas como una desigualdad estructural que presiona en unas $\mathrm{u}$ 
otras direcciones. Para este autor, si la variedad y complejidad de los fenómenos político-discursivos no puede entenderse sin esas relaciones de clase, tampoco puede ser reducible a ellas (Hall 2005b [1983]).

Hall parece más cómodo hablando de "fuerzas sociales". Una fuerza social sería un compuesto de grupos sociales diversos, unidos de manera indefinida en torno a una formación ideológica. Ésta sirve a la fuerza social de aglutinante al mismo tiempo que constituye el medio por el que combate con el resto de fuerzas (Hall 2005a [1986]: 144). Lo ejemplifica a través del thatcherismo, un movimiento que en sus inicios era claramente minoritario y ni siquiera gozaba del favor de la patronal. Tras su consolidación dentro del espacio político tory, su ascenso se caracterizó por una continua conquista de consenso popular gracias a la articulación de doctrina neoliberal y diversos elementos del fragmentario repertorio cultural subalterno - en este caso, británico - que Gramsci (2000) denominaba "sentido común": "nation before class, the organic unity of the English people, the coincidence between the 'English genius' and traditionalism, the paternal duties the privileged owe to the lower orders, society as an orderly hierarchy of 'powers,' constitutionalism, and so on" (Hall 1988: 42). El exitoso resultado del ejercicio thatcheriano del poder no sería otro que el de la consecución de un elevado consenso popular hacia esta particular formación ideológica, es decir, la hegemonía en términos gramscianos.

Aunque pensada para fenómenos alejados del nivel microsocial en el que opera la antropología, la perspectiva halliana abre un camino fértil para analizar las prácticas político-discursivas locales. Para el caso que nos ocupa, por ejemplo, nos permite encuadrar los discursos ganaderos en tanto articulaciones de elementos muy heterogéneos del "sentido común" - la impugnación del latifundismo, la desconfianza hacia el Estado, etc. - nucleadas en torno a una fuerza social que no se explicaría sin el denominador común de su dedicación a la ganadería, pero que al mismo tiempo incluye posiciones tan dispares como la del pequeño ganadero a tiempo parcial y la de la agricultura familiar más acomodada. Y esa articulación es el medio que permite a esta fuerza social combatir discursivamente en su particular campo de fuerzas (Nuijten 2005).

Precisamente la participación clave de las intervenciones estatales en la estructuración de ese campo es la responsable de un doble fenómeno: de la normalización de la preocupación ambiental en tanto elemento del sentido común ganadero y de su posición central en el referido campo. Por lo que respecta a esto último, dicha centralidad no es otra cosa que la específica manifestación de aquella conversión de la sostenibilidad en "anhelo social" de la que hablaba en la introducción. Para Žižek (2003 [1997]), dicha conversión implica la transformación en un poderoso vector de legitimación, pero al precio de la pérdida de gran parte de su anclaje semántico. En ese sentido, las disputas que se producen en torno a la apropiación de dichos anhelos sólo 
pueden consistir en su "perlaboración" (2003 [1997]: 142), ${ }^{5}$ es decir, en su (re)semantización vía articulación en los discursos de lo que Hall denominaría las fuerzas sociales contendientes.

\section{FORCEJEOS EN EL PARQUE}

En este apartado, ofrezco una nueva ilustración del fenómeno objeto de interés, la cual permitirá no sólo profundizar en su densidad, como también mostrar las virtualidades del marco recién expuesto. Revisito la "arena" (Olivier de Sardan 2005) que en este contexto etnográfico representan las reuniones de temática agraria y/o agroambiental. Concretamente, desarrollo un pequeño caso de estudio del tipo "situación social" (Gluckmann 1961) que está protagonizado por un ganadero y el director-conservador del PN en el seno de una jornada organizada por el Centro de Apoyo al Desarrollo Empresarial local. ${ }^{6}$ Si bien las "situaciones sociales" consistían originalmente en la exposición de eventos concretos observados por el/la antropólogo/a al objeto de mejor ilustrar la "morfología de la estructura social" (Gluckmann 1961: 8), aquí se buscará indagar en la complejidad semántica y la dimensión situacional que acompañan a los conflictos (socioambientales) a este nivel microsocial. Ello implicará que no sólo ponga el énfasis sobre las prácticas discursivas de uno de los contendientes, sino que me interese por las de uno y otro en su interrelación.

La jornada en cuestión, titulada significativamente "Gestión sostenible de dehesas", tuvo lugar en noviembre de 2015 en el salón de actos del centro de visitantes del PN. A pesar del rótulo, la sesión estaba dedicada fundamentalmente a los cambios en las ayudas de la PAC derivados de la entrada en vigor del nuevo marco financiero europeo. Había programada una ponencia específica sobre las nuevas "ayudas a la instalación de jóvenes agricultores", la cual debía ser la causa de la asistencia de unos diez o quince muchachos no mayores de 30 años, quienes se sumaban a un número similar de asistentes de mediana edad, todos hombres. Previamente a dicha charla, se produciría la conferencia inaugural, cuyo objeto eran las "potencialidades económicas del PN". Estando a su cargo el director-conservador, sería precisamente a cuenta de ella que emergiese el conflicto.

5 Žižek (2003 [1997]: 139) toma prestado el término "perlaboración" de Freud, quien lo usaba para referirse al proceso por el que el deseo inconsciente que está en la base del sueño es convertido en su texto explícito.

6 El de director-conservador es el puesto de mayor responsabilidad en el organigrama de esta tipología de ANP. El procedimiento de acceso es el de "libre designación", lo cual implica que, a pesar de estar contemplada una valoración de méritos de los funcionarios solicitantes, la decisión final sea a discreción de la correspondiente delegación provincial de la Consejería de Medio Ambiente andaluza. Ya en relación a las funciones que se le adscriben, van desde la coordinación de los proyectos específicos de restauración y conservación a los de educación ambiental, pasando por la supervisión de la tramitación de las autorizaciones y de los expedientes de sanción abiertos por los agentes de medio ambiente. 


\section{Sostenible desarrollo}

El director-conservador, llamado Claudio, comenzó su ponencia enfatizando la excepcionalidad de la comarca donde se ubica el PN a nivel de conservación de los ecosistemas. En ese sentido, subrayó la importancia de las dehesas de la comarca. Claudio reconocía que, en sus inicios, "el parque supuso una condicionalidad extrema para la agricultura y la ganadería”, pero afirmaba que, 25 años después, el hecho de contar con tal figura de protección resultaba más bien una oportunidad.

Como ejemplo ponía el del viñedo, cuya plantación sólo iba a ser permitida por el nuevo régimen estatal de autorizaciones dentro de territorios declarados ANP. Otro ámbito donde el PN demostraba sus beneficios era el de la comercialización de productos. No en vano, el uso de la "marca Parque Natural", un distintivo de calidad para las empresas de los PN andaluces, no paraba de crecer. Claudio también aludió a los beneficios en materia de ayudas. El futuro de la PAC, afirmaba, pasaba por un progresivo condicionamiento ambiental como consecuencia de las presiones de la ciudadanía hacia una agricultura menos contaminante. Efecto de ello era la creciente vinculación entre algunas de esas subvenciones y las ANP, que hacía que muchos ganaderos percibieran una cantidad más elevada de ayuda por la puntuación extra que implicaba su localización en un PN.

Todos esos beneficios, además, no serían algo colateral, sino que formaban parte de los propios objetivos fundacionales del PN, ya que "el compromiso con el desarrollo está inserto desde el principio en su normativa”. Dicho esto, Claudio finalizaba dimensionando el papel del PN respecto a la actividad económica a través de una interpelación a los ganaderos asistentes:

"Todo esto es lo que puede aportar el parque. Y desde el parque intentaremos que cada vez sea más y mejor. Ahora, los que deben llevar el peso de su negocio son los ganaderos. Y para eso hay que innovar y buscar nuevos caminos. Por eso, me gusta mucho lo que suele decir el presidente de la cooperativa de pienso: que de ganaderos hay que pasar a ser empresarios ganaderos" [intervención de Claudio, diario de campo, noviembre de 2015].

En la intervención de Claudio no es difícil detectar una secuencia argumental: (1) excepcionalidad de los ecosistemas locales; (2) PN como responsable de su protección y del asociado "condicionamiento" de la actividad agraria; (3) PN, también, como factor positivo para esa actividad; (4) compatibilidad, por tanto, entre protección ambiental y desarrollo económico (desarrollo sostenible); y (5) llamada a un cambio en la mentalidad de los productores agrarios. Sin duda, este desarrollo discursivo estaba dirigido a alejar al PN de la extendida identificación por parte del sector ganadero como un organismo 
fundamentalmente represivo y a avanzar en la construcción de consenso alrededor del mismo.

En esta jugada, considero que tiene un papel crucial la particular lectura que realiza Claudio de la noción de desarrollo sostenible. Dada la inherente insostenibilidad del sistema capitalista, varios autores han destacado el carácter de contradicción en términos de dicha noción. Un carácter que tendría que ver con su intrahistoria, es decir, con su vinculación con un proceso de "perlaboración" de la preocupación ambiental por el que se generó una suerte de "máscara" de la ideología del crecimiento económico (Santamarina 2006: 124). Dicha perlaboración, sin embargo, no agota otras alternativas y éste es precisamente el caso de la lectura efectuada por Claudio. En ella, contrariamente a la versión neoliberal, es el desarrollo el que se supedita a la prioridad conservacionista. De ahí que su referencia al "condicionamiento extremo" a la actividad agraria en los primeros años del PN no sirviese sólo para situar la limitación más cuestionable en el pasado, sino también para asentar la imagen de la protección ambiental como una continuidad inevitable. ${ }^{7}$ Ello, además, se acompañaba de la implícita asignación de dicha tarea al PN.

A pesar de su posición subalterna en el resemantizado tándem, el desarrollo económico desempeña un importante papel en el discurso de Claudio. Sus alusiones a la posibilidad excepcional de plantación, a las potencialidades comerciales de la marca Parque Natural y a las ayudas PAC remiten a la idea de "progreso" (económico), que constituye uno de los elementos clave del sentido común al que Claudio parece apelar para construir una imagen del PN como un aliado. Ahora bien, el director se cuidaba mucho de identificar al PN como el motor del desarrollo local. No es que asumiese sin más el hecho de que, sin estar dotados de capacidad presupuestaria, la posibilidad de intervención económica directa de estos organismos sea prácticamente nula, sino que iba más allá e interpelaba a los ganaderos en tanto "emprendedores", es decir, en tanto "sujetos de responsabilidad, autonomía y elección" (Rose 2006: 155). Recuérdese su frase: "hay que innovar y buscar nuevos caminos [...] de ganaderos hay que pasar a ser empresarios ganaderos".

Más allá del envoltorio de foucaultiana gubernamentalidad neoliberal, lo que parece querer deslizar esa interpelación es una distribución de las responsabilidades de cara al desarrollo sostenible por la que el desarrollo, si bien facilitado estructuralmente por el PN, recae sobre los ganaderos y el PN queda como el depositario legítimo de la otra tarea: el "condicionamiento" derivado de la indiscutible necesidad de protección ambiental. Aquí es donde

7 Santamarina observa este mecanismo en toda iniciativa de patrimonialización natural: "En la formulación de los espacios naturales se dan por asumidas al menos dos consideraciones fundamentales: la 'naturaleza' es evidente (proceso de objetivación) y la 'protección' es indiscutible (proceso de intervención)” (2009: 306-307). 
encontramos el verdadero objetivo de Claudio: la legitimación del PN entre los ganaderos. Algo, por cierto, que no era casual. En una entrevista que le realicé unos meses antes me decía en relación a lo que denominaba "los sectores más o menos reticientes" con el PN: "yo no los veo como enemigos, sino más bien como grupos con los que tenemos que establecer alianzas".

\section{La manufactura del ecosistema}

Antes de que se abriese el turno de preguntas, un ganadero ya tenía la mano levantada. Comenzó su intervención diciendo: "Las palabras que ha dicho el director del parque son palabras bonitas que yo ya he escuchado otras veces..." El rostro de Claudio, que parecía saludar con interés la intervención del ganadero, adoptó rápidamente un aire defensivo. El ganadero, llamado Joaquín, prosiguió reconociendo que, en un inicio, estuvo a favor del PN "porque parque natural y medio ambiente son palabras bonitas y fuertes". No obstante, pronto dejó de estarlo, "porque el parque natural, hasta ahora, sólo le ha metido el miedo en el cuerpo a los empresarios". Con ello se refería a que la presión del PN resultaba excesiva. Había tantas normas que seguir que los ganaderos nunca sabían a ciencia cierta si se encontraban libres de posibles sanciones. Tampoco sabían cuándo podía producirse la visita de un agente del PN, ya que patrullaban por cualquier camino y solían entrar, sin previo aviso ni permiso, en sus explotaciones.

Joaquín solía ofrecer abstractas referencias que dibujaban un ambiente opresivo y arbitrario. Por medio de esta retórica modulaba un elemento de fuerte arraigo en el sentido común, el de la fragilidad del individuo ante el ejercicio del poder. A la buscada legitimación por Claudio de la autoridad del PN, Joaquín oponía de esta forma una caracterización de ese ejercicio como un fenómeno discrecional. Ello conectaba directamente con la percepción generalizada entre los ganaderos, en la que es clave la circulación de relatos que refieren a la ubicuidad y arbitrariedad de la acción de los agentes del PN. He aquí un ejemplo extraído de una visita de campo que realicé a la explotación de unos medianos ganaderos. Mientras desvaretaba olivos junto a un empleado, el hermano mayor señalaba a unos troncos de eucalipto cortados:

"[...] para poder cortarlos, debían pedir dos permisos: el de corta y el de quema. El primero que llegó fue este último, así que dio por hecho que permitían la corta y los cortó. Sin embargo, fue multado. Y añade que el técnico del Parque que vino a comunicarle la multa, venía ya con las dimensiones de los troncos anotadas, lo cual demuestra que había entrado previa e ilegalmente en el olivar para hacer esas mediciones" [diario de campo, abril de 2014].

Como vemos, la jugada discursiva de Claudio se topó con una réplica bien anclada en la negativa experiencia del PN; una experiencia que iba más 
allá de la amenaza de sanciones y que tenía que ver con una mala gestión administrativa. Precisamente en este último sentido, Joaquín aludía a un arrendador de fincas conocido en la comarca por dejarlas en un grave estado de deterioro. El ganadero se preguntaba si el PN, que decía proteger el medio ambiente, no había detectado ese comportamiento y tomado cartas en el asunto. Joaquín contraponía este tipo de omisiones al papel que los ganaderos jugaban para el medio ambiente. Serían precisamente ellos quienes harían posible el mantenimiento de aquello que el PN decía proteger con su trabajo diario. Y lo que era más: "Si existe la dehesa, es porque nuestros antepasados plantaron los árboles y metieron ganado en estos pagos [campos]".

Algo muy interesante en el desarrollo discursivo de Joaquín es que, en lugar de rechazar la premisa de Claudio - el medio ambiente como inherentemente necesitado de protección -, la asume y rearticula. Recordemos que Claudio hacía desembocar esa necesidad de protección en la legitimación de la patrimonialización y, por tanto, en el exclusivismo proteccionista del PN. Si, con la previa articulación de la impugnación del ejercicio del poder, Joaquín cuestionaba la forma en que dicha tarea era implementada, mediante el ejemplo del conocido arrendador que esquilmaba una finca tras otra, atacaba la capacidad misma del PN para llevarla a cabo. El PN era así representado con la potente imagen de una "figura de protección que no protege".

Frente a esa inutilidad, Joaquín destacaba el papel de los ganaderos. La base del mantenimiento del medio ambiente sería precisamente su actividad productiva. Como en el relato de Tomás que vimos en la introducción, la táctica de Joaquín pasaba por subrayar el carácter tangible de su acción ambiental frente a quienes no materializaban sus declaraciones o incluso se inhibían de sus presuntas responsabilidades. Joaquín, además, no se quedaba en el presente, sino que establecía una genealogía con aquéllos que transformaron el paisaje previo a la dehesa ("Si existe la dehesa, es porque nuestros antepasados plantaron los árboles y metieron ganado en estos pagos").

En síntesis, puede decirse que, si el discurso del director replicaba las típicas premisas conservacionistas - (1) el medio ambiente existe; (2) el medio ambiente debe ser protegido; (3) el PN es el encargado de la protección del medio ambiente -, Joaquín no oponía otras. Más bien, procedía a ofrecer un desarrollo alternativo: (1) el medio ambiente existe; (2) sus constructores fueron nuestros antepasados; (3) el medio ambiente debe ser protegido; (4) los ganaderos siguen siendo los encargados de su protección. En el fondo, el objetivo, tanto de Claudio como de Joaquín, es el de adherir al significante consensual, "no-ideológico", del medio ambiente, un contenido disputado - las restricciones del PN, la acción agraria de los ganaderos - y así efectuar una transferencia de legitimidad por la que uno u otro agente se convertirían en el protector (legítimo) del medio ambiente. 


\section{El repliegue de Claudio}

La intervención del ganadero fue interrumpida por Claudio para, según dijo, tener derecho a responder y no pisar el tiempo del resto de ponencias programadas. Visiblemente molesto por unas críticas que había escuchado en repetidas ocasiones, Claudio intentó desmontar la afirmación sobre la presión excesiva que se atribuía al PN. Reconocía que el hecho de encontrarse dentro de un ANP hacía que el monto de las multas se doblase y que del asunto se pudiese encargar una fiscalía especializada. Ahora bien, ofrecía el dato de que en el año anterior sólo 185 de los cinco mil expedientes que se habían abierto se habían saldado con una sanción. Claudio, por tanto, decía no ver ni "punitividad", ni motivos para el miedo:

"Nadie puede decir que tiene un agente [de medio ambiente] pegado a la espalda. Más bien, hay menos de los que debería, porque la administración ambiental se ha visto particularmente perjudicada por los recortes y esto supone que no se pueda hacer la labor de guardería de la mejor manera" [diario de campo, noviembre de 2015].

Dicho esto, Claudio pasó al cuestionamiento de ciertas acciones que imputaba a los habitantes de la comarca. Aludió, por ejemplo, al hecho de que existiesen muchas fincas sobreexplotadas. Decía no entender tampoco las críticas de los habitantes de la comarca a las supuestas malas prácticas de los visitantes foráneos. Éstas podían existir, "pero en el Cerro del Hierro [lugar de reconocido valor ambiental del PN] han encontrado una lavadora tirada y en fincas se han encontrado encinas cortadas por el tronco, ¿eh?" Claudio decía estar sorprendido ante la falta de denuncias respecto a unos actos que sólo podían haber sido realizados por residentes.

Como vemos, el cambio entre la primera y segunda intervención del director-conservador es considerable. Si la primera estaba marcada por una serie de guiños a los ganaderos como parte de su buscada "alianza", el enfado lo llevaría a olvidar ese proyecto y realizar una defensa del PN consistente en el ataque a los propios ganaderos. Sin responder a la acusación de inacción ante la sobreexplotación, Claudio les devolvía esta misma crítica, atacando así la imagen construida por Joaquín de los ganaderos como protectores-constructores de la dehesa. Si de esta manera Claudio conseguía atacar el discurso "legitimista" de Joaquín, al mismo tiempo perdía de vista a los destinatarios de su jugada original, los propios ganaderos.

En esa línea, Claudio etiquetaba las críticas que veían en el PN un obstáculo al desarrollo como "conversaciones de barra de bar". Si se consultasen los estudios científicos comparativos realizados hasta la fecha, decía, se comprobaría que, en zonas paisajísticamente similares a los PN pero sin esa figura de protección, la riqueza era mucho menor. Tras esta evocación del "saber experto", 
cerraba adoptando un tono entre conciliador y paternalista para agradecer la intervención del asistente, porque "discutir sobre el parque es también una forma de evaluarlo", y lanzaba la propuesta de celebración de un foro en el que se debatiese específicamente sobre el PN.

\section{Área (no) protegida}

La palabra volvió a Joaquín, quien recogió el guante de la propuesta de foro de debate. Aunque decía no querer extenderse para evitar perjudicar el desarrollo de la jornada, sí quería dejar varios temas sobre la mesa. A partir de unas anotaciones en su cuaderno, se los lanzó a Claudio a través de una enumeración rápida: "la pérdida de fauna, la nevada, el 'camión pestoso' y la seca”. Justo después, se sentó a la espera de respuesta.

Con la pérdida de fauna, refería a la percepción generalizada en la comarca de una creciente disminución del número de animales. Con la nevada, a un fuerte temporal de nieve ocurrido algunos años atrás, el cual había producido graves daños en algunas fincas como consecuencia de la caída de ramas. La administración, según la opinión local, tardó en actuar y las prometidas ayudas para hacer frente al perjuicio económico nunca llegaron. La "seca", por su parte, refería a un fenómeno patológico en expansión por el que encinas y alcornoques sufren un decaimiento y mueren. Por último, el "camión pestoso" aludía a un camión para cadáveres de animales que recorría periódicamente la localidad.

La articulación de estos cuatro elementos no era una mera agrupación de figuras diversas y representativas de deterioro ambiental. Dirigiéndose a Claudio en tanto director-conservador, todas ellas se hacían girar sobre la impugnación del PN. Tal "condensación" (Laclau 1978: 114-115) fue evidenciada repetidamente a lo largo del trabajo de campo y, a través de ella, el PN se convertía en el blanco de toda cuestión susceptible de ser caracterizada como ambiental. En cierta manera, da la impresión de que nos encontramos ante el reverso del exclusivismo en materia de protección ambiental que es común en la implementación de toda ANP (ver nota al pie 7) y que constituía la premisa para la que Claudio quería ganar el consenso ganadero.

Claudio, en su respuesta, volvía a apoyarse en el saber experto, haciendo alusión, en su tratamiento de la cuestión de la "biodiversidad", a estudios científicos que rechazaban la realidad descrita por Joaquín. También renovaba la referencia a comportamientos ambientalmente incorrectos entre los ganaderos, apuntando a la correlación entre fincas abandonadas productivamente y mayor incidencia de la seca. El discurso, como no podía ser de otra manera, se orientaba a segregar al PN de las problemáticas ambientales señaladas por Joaquín. En el caso de la nevada, Claudio incluso se sumaba a la crítica a la "administración". De alguna forma, lo que el director buscaba era deshacer la "condensación" que convertía al PN en el blanco de esas demandas cuyo denominador común era el deterioro ambiental. No obstante, la cuestión no 
era que esa particular construcción se apoyaría en un mero desconocimiento del ámbito de actuación del PN, el cual, una vez aclarado, la disolvería. Lo que estaba en juego no eran las tareas de conservación reales que la normativa adjudicaba al PN, sino, como decía más arriba, el papel que el propio Claudio había querido arrogar al PN, su pretensión de monopolio de la labor de protección del medio ambiente.

\section{NOTAS CONCLUSIVAS}

El caso desarrollado en el anterior apartado nos ha permitido profundizar en la particular forma que el fenómeno de la ambientalización adopta en el caso de los ganaderos de Cazalla. Si el director-conservador realizaba una articulación discursiva tendente a asociar la conservación como premisa con la labor del PN, el ganadero realizaba un ejercicio discursivo paralelo por el que, aceptando tal premisa, ésta era (re)articulada a diferentes elementos del sentido común - la impugnación del ejercicio arbitrario del poder, las memorias sociales agrarias, etc. - para defender unos "intereses" (Hall 1988: 45) que, en este caso, tienen que ver con la continuidad de unas explotaciones (Edelman 2005) crecientemente intervenidas por políticas de corte ambiental.

Lo que vemos, por tanto, es cómo este proceso de ambientalización local tiene que ver con la disputa por la preocupación ambiental en tanto ésta se ha convertido en uno de los significantes centrales en nuestra sociedad en general y en el campo agrario en particular. Al igual que términos como democracia o justicia, la preocupación por los límites ambientales y la sostenibilidad - el anverso propositivo de esa preocupación - constituyen un nuevo "anhelo social” que contiene la suficiente ambigüedad semántica como para constituirse en elemento central de los combates discursivos. Sintéticamente, podría decirse que, al haberse convertido esa dupla en un "significante no-ideológico" (Žižek 2003 [1997]), la lucha se produce en torno a él.

Asumiendo ese anhelo hasta el punto de adoptar las premisas conservacionistas, el proceso descrito en este artículo debe ser entendido como la emergencia de un ambientalismo que se genera desde el interior mismo del medio rural. Ello no sólo apunta hacia una pluralización de los ecologismos, sino que, de manera crucial, implica el movimiento de un sector social clave hacia posiciones que hacen posible una alianza estratégica con el movimiento ecologista y el resto de actores sociales que empujan hacia un mundo sostenible. Sin abandonar la preocupación por los problemas ecológicos de la dehesa actual, ello requeriría que estos actores asumiesen plenamente la profunda e histórica vinculación de los sectores agrarios serranos con su entorno y la relevancia de su lucha por el mantenimiento de su intervención sobre el mismo en tanto realidad intrínsecamente socioambiental. 


\section{BIBLIOGRAFÍA}

ACOSTA, Rufino, 2002, Los Entramados de la Diversidad: Antropología Social de la Dehesa. Badajoz, Diputación de Badajoz.

AGRAWAL, Arun, 2005, "Environmentality: community, intimate government, and environmental subjects in Kumaon, India”, Current Anthropology, 46 (2): 161-190.

ANAYA, Felisa, y Mário ESPÍRITO-SANTO, 2018, "Protected areas and territorial exclusion of traditional communities", Ecology and Society, 23 (1): 8.

CEPEK, Michael, 2011, "Foucault in the forest: questioning environmentality in Amazonia", American Ethnologist, 38 (3): 501-515.

COCA, Agustín, 2014, "Los procesos de patrimonialización natural en cuestión: legitimidad y uso de los recursos en el PN Los Alcornocales (Andalucía)", Arxius de Ciències Socials, 30: 31-44.

CORTES-VAZQUEZ, José A., 2012, Naturalezas en Conflicto: Conservación Ambiental y Enfrentamiento Social en el Parque Natural Cabo de Gata-Níjar. Valencia, Germania.

CORTES-VAZQUEZ, José A., y Esteban RUIZ-BALLESTEROS, 2018, "Practising nature: a phenomenological rethinking of environmentality in natural protected areas in Ecuador and Spain", Conservation and Society, 16 (3), 232-242.

DE CERTEAU, Michel, 1984 [1980], The Practice of Everyday Life. Berkeley y Los Angeles, University of California Press.

DE VRIES, Pieter, 2005, “Critiquing governmentality: the social construction of participation and accountability in the Atlantic zone of Costa Rica”, Focaal, 45: 94-11 1.

DÍAZ, Pablo, Agustín SANTANA, y Alberto RODRÍGUEZ, 2015, "Re-significando lo cotidiano, patrimonializando los discursos”, Desacatos, 47: 72-89.

EDELMAN, Marc, 2005, "Bringing the moral economy back in... to the study of 21 st-century transnational peasant movements", American Anthropologist, 107 (3): 33 1-345.

GARCÍA, Josefa, 2005, "El último decenio: aplicación y consecuencias de las reformas de la PAC”, en José Luis García y Josefa García (coords.), Política Agraria Común: Balance y Perspectivas. Barcelona, La Caixa, 44-69.

GLUCKMANN, Max, 1961, "Ethnographic data in British social anthropology”, The Sociological Review, 9 (1): 5-17.

GRAMSCI, Antonio, 1984, "Cuaderno 8", en Antonio Gramsci, Cuadernos de la Cárcel, vol. 3. México, DF, Era, 211 -348.

GRAMSCI, Antonio, 2000, “Cuaderno 27: observaciones sobre el 'folklore'”, en Antonio Gramsci, Cuadernos de la Cárcel, vol. 6. México, DF, Era, 201-207.

HALL, Stuart, 1988, "The toad in the garden: Thatcherism among the theorists", en Cary Nelson y Lawrence Grossberg (coords.), Marxism and the Interpretation of Culture. Champaign, University of Illinois, 35-57.

HALL, Stuart, 2005a [1986], “On postmodernism and articulation: an interview with Stuart Hall”, en David Morley y Kuan-Hsing Chen (coords.), Stuart Hall: Critical Deba-

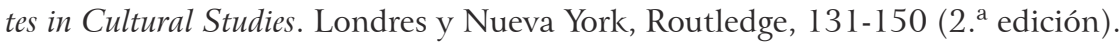

HALL, Stuart, 2005b [1983], "The problem of ideology: Marxism without guarantees", en David Morley y Kuan-Hsing Chen (coords.), Stuart Hall: Critical Debates in Cultural Studies. Londres y Nueva York, Routledge, 24-45 (2. ${ }^{\text {a }}$ edición).

JOFFRE, Richard, et al., 1988, "The dehesa: an agrosilvopastoral system of the Mediterranean region with special reference to the Sierra Morena area of Spain", Agroforestry Systems, 6: 71-96. 
LAClAU, Ernesto, 1978, Política e Ideología en la Teoría Marxista: Capitalismo, Fascismo, Populismo. Madrid, Siglo XXI.

LACLAU, Ernesto, 2005, La Razón Populista. Buenos Aires, FCE.

LONG, Norman, 2001, Development Sociology: Actor Perspectives. Londres y Nueva York, Routledge.

LOPES, José Leite, 2006, "Sobre os processos de 'ambientalização' dos conflitos e sobre dilemas da participação”, Horizontes Antropológicos, 25: 31-64.

NUIJTEN, Monique, 2005, "Power in practice: a force field approach to natural resource management", The Journal of Transdisciplinary Environmental Studies, 4 (2): 1-14.

OLIVIER DE SARDAN, Jean-Pierre, 2005, Anthropology and Development: Understanding Contemporary Social Change. Londres y Nueva York, Zed Books.

ROSE, Nikolas, 2006, "Governing 'advanced' liberal democracies", en Aradhana Sharma y Akhil Gupta (coords.), The Anthropology of the State: A Reader. Oxford, Blackwell, 144-162 (2. ${ }^{\text {a }}$ edición).

RUIZ-BALLESTEROS, Esteban, et al., 2009, "Naturalizing the environment: perceptual frames, senses and resistance", Journal of Material Culture, 14 (2): 147-167.

SANTAMARINA, Beatriz, 2006, Ecología y Poder: El Discurso Medioambiental como Mercancía. Madrid, Catarata.

SANTAMARINA, Beatriz, 2009, "De parques y naturalezas: enunciados, cimientos y dispositivos”, Revista de Dialectología y Tradiciones Populares, LXIV (1): 297-324.

SANTAMARINA, Beatriz, y Oriol BELTRAN, 2016, "Heritage and knowledge: apparatus, logic and strategies in the formation of heritage", Anthropological Forum, 26 (4): 397-414.

SCOTT, James C., 1985, Weapons of the Weak. Everyday Forms of Peasant Resistance. New Haven y Londres, Yale University Press.

SILVA, Luís, 2015, "Foucault in the landscape: questioning governmentality in the Azores", Landscape Research, 40 (4): 397-410.

SINGH, Neera, 2013, "The affective labor of growing forests and the becoming of environmental subjects: rethinking environmentality in Odisha, India”, Geoforum, 47: 189-198.

SUTHERLAND, Lee-Ann, e Ika DARNHOFER, 2012, “Of organic farmers and 'good farmers': changing habitus in rural England”, Journal of Rural Studies, 28 (3): 232-240.

WHITEHOUSE, Andrew, 2009, “'A disgrace to a farmer': conservation and agriculture on a nature reserve in Islay, Scotland”, Conservation and Society, 7 (3): 165-175.

ŽIŽEK, Slavoj, 2003 [1997], "Multiculturalismo, o la lógica cultural del capitalismo multinacional”, en Fredric Jameson y Slavoj Žižek, Estudios Culturales: Reflexiones sobre el Multiculturalismo. Buenos Aires, Paidós, 137-188.

\footnotetext{
Receção da versão original / Original version

Receção da versão revista / Revised version

Aceitação / Accepted
}

$2018 / 05 / 09$

$2018 / 12 / 31$

$2019 / 04 / 08$ 